\title{
Evaluation of treatment response and tissue necrosis as prognostic indicators following neoad- juvant chemoradiotherapy in rectal cancer patients
}

Ji-Han Jung ${ }^{1}$, Ho Jung An², Hyung-Jin Kim³ ${ }^{3}$ Jonghoon Lee ${ }^{4}$, Kang-Moon Lee ${ }^{2}$, Sung Hwan Kim ${ }^{4}$, Hyeon-Min $\mathrm{Cho}^{3}$, and Byoung Yong Shim ${ }^{2}$

Departments of ${ }^{1}$ Hospital Pathology, ${ }^{2}$ Internal Medicine, ${ }^{3}$ General Surgery, and ${ }^{4}$ Radiation Oncology, College of Medicine, The Catholic University of Korea, Seoul, Korea

Received: September 3, 2014 Revised : November 11, 2014 Accepted: December 5, 2014

\section{Correspondence to}

Byoung Yong Shim, M.D.

Department of Internal Medicine, College of Medicine, St. Vincent's Hospital, The Catholic University of Korea, 93 Jungbu-daero, Paldal-gu, Suwon 16247, Korea

Tel: +82-31-249-8153

Fax: +82-31-253-8898

E-mail:shimby@catholic.ac.kr
Background/Aims: The objective of this study was to assess the prognostic roles of treatment response and tissue necrosis after chemoradiotherapy (CRT) in locally advanced rectal cancer.

Methods: A total of 243 patients with locally advanced rectal cancer who underwent neoadjuvant CRT were included. Three treatment response groups were classified by their pathological stage results: complete treatment response (CTR), intermediate treatment response (ITR), and poor treatment response (PTR). Three tissue necrosis groups were classified based on tissue pathological results: complete necrosis response (CNR), intermediate necrosis response (INR), and poor necrosis response (PNR).

Results: Overall survival (OS) and recurrence-free survival (RFS) rate at three years were $74.5 \%$ and $61.3 \%$, respectively. The 3-year OS rates of the CTR, ITR, and PTR groups were 83.7\%, 75.9\%, and 69.7\%, respectively ( $p<0.001$ ); the 3-year RFS rates were $76.7 \%, 69.0 \%$, and $52.1 \%$, respectively $(p<0.001)$. The 3-year OS rates of the CNR, INR, and PNR groups were $83.7 \%, 80.6 \%$, and $61.8 \%$, respectively ( $p<0.001$ ); the 3-year RFS rates were $76.7 \%, 68.9 \%$, and $44.3 \%$, respectively $(p<0.001)$. When compared to CTR/CNR, PTR/PNR was strongly related to an increased risk of recurrence (hazard ratio [HR], 5.53; 95\% confidence interval [CI], 2.01 to 15.23 vs. HR, 6.37; 95\% CI, 2.29 to 17.74, respectively) in univariate Cox regression. Both PTR and PNR were strongly associated with shorter RFS and OS when compared with CTR and CNR in the multivariate Cox regression.

Conclusions: Tissue necrosis is an equally important prognostic marker as treatment response for oncologic outcomes in locally advanced rectal cancer.

Keywords: Rectal neoplasms; Chemoradiotherapy; Necrosis

\section{INTRODUCTION}

Over the past decade, improvement in local control and overall survival (OS) of rectal cancer has been achieved by the development of multimodality therapies such as neoadjuvant chemoradiotherapy (CRT), adjuvant
CRT and surgery [1]. The development of surgical techniques such as total mesorectal excision (TME) and laparoscopic surgery, and of radiologic techniques including three-dimensional conformal radiotherapy, intensity-modulated radiotherapy, and dynamic intensity-modulated radiotherapy, has resulted in reduced 
complications and increased effects of treatment for advanced rectal cancer [2-5]. Treatment of rectal cancer with neoadjuvant 5-fluorouracil (5-FU) CRT prevents local recurrence and may increase the success of sphincter-conserving surgery. Recently oxaliplatin and irinotecan were introduced as a new combination regimen of neoadjuvant CRT, in place of 5 -FU, which has been the conventional treatment option; however, the benefits of this new regimen remain controversial [6-8].

The association between pathological response, which is evaluated after radical tumor resection, and patient prognosis has been well established. Emerging data suggest that the complete response observed in approximately $15 \%$ to $20 \%$ of patients treated with neoadjuvant CRT is associated with local control and survival [9]. Additionally neoadjuvant treatment response can be an early prognosis indicator for patients with rectal cancer [10].

Many previous reports examining response indicators for rectal cancer used data from several institutes and various treatment strategies [11,12]. Multi-institutional bias and variation in treatment strategy may have affected data analysis. A single-institution experience with homogenous treatment and pathological evaluation can avoid some bias. Generally, initial clinical staging of rectal cancer patients determines the adjuvant chemotherapy regimen and treatment plan schedule according to guidelines and pathological staging of patients using determinants of cancer-related survival. In Korea, 5-FU plus leucovorin (FL) chemotherapy is reimbursed only for one regimen of adjuvant chemotherapy in rectal cancer. Therefore, improving the understanding of prognostic factors and response to neoadjuvant CRT will help practitioners plan adjuvant treatment.

The aim of this study was to evaluate prognostic clinical and pathological factors in locally advanced rectal cancer treated with neoadjuvant CRT. Additionally, we minimized bias by conducting the study at a single institution with standard treatments such as TME and laparoscopic surgery, and by ensuring all patients received the same CRT.

\section{METHODS}

\section{Patients and treatment}

We used a retrospective cohort method in patients with biopsy-proven, locally advanced stage II and III rectal cancer. The study population consisted of 243 rectal cancer patients who underwent neoadjuvant CRT and laparoscopic surgery at St. Vincent's Hospital between January 2001 and December 2008. Patient charts, radiographic findings, and postoperative pathological slides were reviewed. Inclusion criteria were: available archival paraffin-embedded tissue samples of initial colonoscopic biopsy, neoadjuvant treatment with 50.4 Gy (1.8 Gy/day in 28 fractions) over 5.5 weeks, plus 5-FU (400 mg/ $\mathrm{m}^{2} /$ day) and leucovorin ( $20 \mathrm{mg} / \mathrm{m}^{2} /$ day) bolus on days 1 to 5 and 29 to 33 , surgery performed 7 to 10 weeks after completion of all therapies for all patients, and follow-up for at least 2 years for patients with clinical stage II-III rectal cancer.

\section{Clinical staging and pathological evaluation}

All patients had an initial work-up before CRT that included abdominal computed tomography (CT), chest $\mathrm{CT}$, positron emission tomography-CT, pelvis magnetic resonance imaging (MRI), and endorectal ultrasound. The initial clinical stage was decided comprehensively using these data. Patients also had a presurgical workup that included pelvis MRI and endorectal ultrasound. A single surgical team, assisted by surgical residents in training, performed TME using laparoscopy. The quality of TME was classified as complete, near-complete, or incomplete. All patients had more than near-complete excision. Clinical stage and follow-up recurrence were performed in an independent review conducted by a radiologist. Pathological stage, grade, and other pathological parameters were reviewed by two independent pathologists. Complete response was defined as the absence of viable tumor cells in the surgical specimen. Down-staging was defined as staging reduction from pretreatment stage (cStage) to pathological staging (ypStage) (i.e., cIII to ypII, ypI or ypo, cII to ypI or ypo).

For treatment response factors, patients were classified into three treatment response groups based on their pathological results: ypToNo was classified as complete treatment response (CTR), ypT1-2No was classified as intermediate treatment response (ITR), and ypT3-4No or ypTanyN+ were classified as poor treatment response (PTR).

For tissue necrosis factors, pathological tissue response to CRT was reviewed and scored as follows: grade 
o, no response; grade 1 , necrosis or disappearance of tumor cells less than $2 / 3$; grade 2 , necrosis or disappearance of tumor cells more than $2 / 3$; and grade 3 , no viable cells (ypCR). Patients were classified into three tissue necrosis groups on the basis of their tissue pathological results: grade 3 was classified as complete necrosis response (CNR), grade 2 was classified as intermediate necrosis response (INR), and grade 1 or o were classified as poor necrosis response (PNR). Tumor necrosis grading is shown in Fig. 1.

\section{Statistical analysis}

Response outcomes for each tumor-related variable as well as the pathological response rate following CRT were compared using the Wilcoxon rank-sum test. The Kruskal-Wallis test was used for multiple predictor and response groups. Categorical data were summarized by frequency within each cohort, and comparisons were performed using the chi-square test for proportions. The test for binary correlation was used to assess associations between selected polynomial categorical variables. Correlation analysis was performed using Pearson chi-square or Fisher exact test. Recurrence-free survival (RFS) and OS were calculated using the Kaplan-Meier method. Simple variable analysis was performed using the log-rank method and multivariate analysis with the Cox regression model. Survival rates and odds ratios

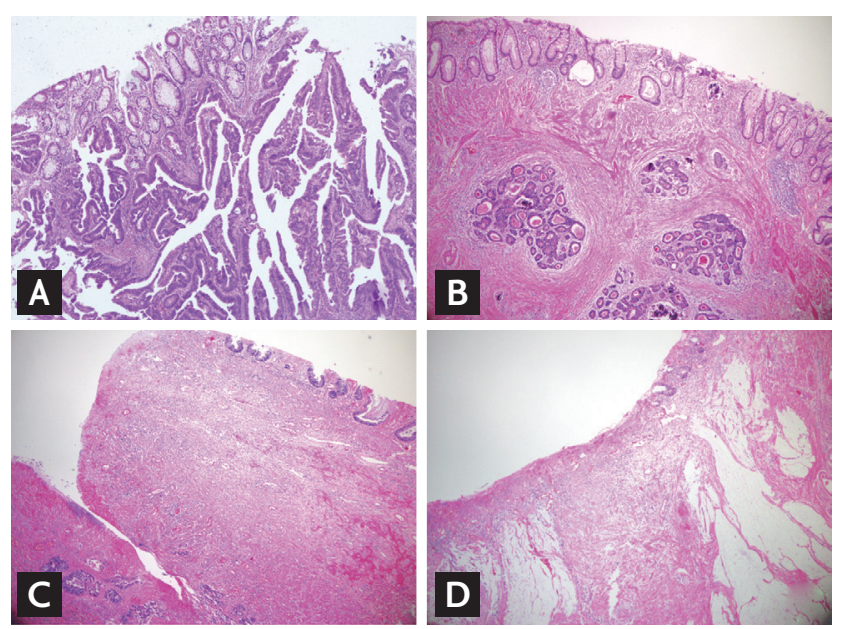

Figure 1. Tumor necrosis grading. (A) Grade $\mathrm{O}$, no response (H\&E, $\times 40)$. (B) Grade 1, necrosis or disappearance of less than 2/3 of tumor cells (H\&E, $\times 40$ ). (C) Grade 2, necrosis or disappearance of more than $2 / 3$ of tumor cells $(\mathrm{H} \& \mathrm{E}, \times 4 \mathrm{O})$. (D) Grade 3, no viable cells (H\&E, × 40). are presented with $95 \%$ confidence intervals (CIs). IBM SPSS version 21.o (IBM Co., Armonk, NY, USA) was used for statistical analysis.

\section{RESULTS}

\section{Patient characteristics and pathological responses}

This study included 149 male and 94 female patients with a median age of 62 years (interquartile range [IQR], 52 to 69). Clinical stages II and III accounted for 116 patients (47.7\%) and 127 patients (52.3\%). Most patients underwent laparoscopic abdominal transanal protosigmidectomy with coloanal anastomosis (LATA), laparoscopic low anterior resection (LA LAR), and laparoscopic abdominoperineal resection (LA APR). At a median follow-up period of 54 months (IQR, 36 to 77), 182 patients (74.9\%) were alive. The overall recurrence rate was 30\% (73 patients). Ten patients (4.1\%) had loco-regional recurrence, 52 patients $(21.4 \%)$ had distant metastasis, and 11 patients (4.5\%) had both local and distant recurrence. The down-staging rate of this neoadjuvant therapy was $57.6 \%$ (140 patients) and ypCR was $17.7 \%$ (43 patients). RFS and OS did not reach the median. Median carcinoembryonic antigen (CEA) was $3.71 \mathrm{ng} / \mathrm{mL}$ (IQR, 2.0 to 10.6) and median lactate dehydrogenase (LDH) was $283 \mathrm{IU} / \mathrm{L}$ (IQR, 235 to 327). Patient characteristics and response to neoadjuvant treatment are summarized in Table 1.

\section{Pathological results and patient characteristics according to treatment response group}

Pathological stage was ypToNo in 43 patients (17.7\%), ypT1-2No in 71 patients (29.3\%), ypT3-4No in 76 patients (31.3\%), and any ypT with $\mathrm{N}+$ in 66 patients (27.2\%). The ypN+ tumor accounted for two ypT1 tumors (3.0\%), 11 yp'2 tumors (16.7\%), and 53 ypT3-4 tumors (80.3\%). Treatment response was recorded as follows: CTR in 43 patients (17.7\%), ITR in $5^{8}$ patients (23.9\%), and PTR in 142 patients $(58.4 \%)$.

Age and sex were not significantly different between the three treatment response groups. However, lymphatic invasion and perineural invasion of tumor tissue were more frequently observed in the poor treatment group $(p<0.001)$. The detailed relationships between the clinicopathological features and treatment response are provided in Table 2. 
Table 1. Patient characteristics and response after neoadjuvant chemoradiotherapy for advanced rectal cancer $(n=243)$

\begin{tabular}{|c|c|}
\hline Characteristic & No. (\%) \\
\hline Age, median (IQR), $\mathrm{yr}^{\mathrm{a}}$ & $62(52-69)$ \\
\hline \multicolumn{2}{|l|}{ Sex } \\
\hline Male & $149(61.3)$ \\
\hline Female & $94(38.7)$ \\
\hline \multicolumn{2}{|l|}{ Operation name } \\
\hline $\begin{array}{l}\text { Laparoscopic abdominal transanal } \\
\text { protosigmidectomy with coloanal } \\
\text { anastomosis }\end{array}$ & $103(42.4)$ \\
\hline Laparoscopic low anterior resection & $85(35 \cdot 0)$ \\
\hline $\begin{array}{l}\text { Laparoscopic abdominoperineal } \\
\text { resection }\end{array}$ & $38(15.6)$ \\
\hline Other & $17(7.0)$ \\
\hline \multicolumn{2}{|l|}{ Location of tumor (cm, from anal verge) } \\
\hline$<5$ & $80(32.9)$ \\
\hline$\geq 5$ & $163(67.1)$ \\
\hline \multicolumn{2}{|l|}{ Differentiation } \\
\hline Well & $45(18.5)$ \\
\hline Moderate & $167(68.7)$ \\
\hline Poorly & $31(12.8)$ \\
\hline \multicolumn{2}{|l|}{ Clinical stage } \\
\hline II & $116(47 \cdot 7)$ \\
\hline III & $127(52 \cdot 3)$ \\
\hline \multicolumn{2}{|l|}{ Tumor pathology } \\
\hline Lymphatic invasion & $35(14 \cdot 4)$ \\
\hline Perineural invasion & $32(13.2)$ \\
\hline Vascular invasion & $7(2.9)$ \\
\hline \multicolumn{2}{|l|}{ Tissue response evaluation } \\
\hline Grade o: no change & $15(6.2)$ \\
\hline Grade 1 : necrosis in less than $2 / 3$ tumor & $82(33.7)$ \\
\hline $\begin{array}{l}\text { Grade } 2 \text { : necrosis in more than } 2 / 3 \\
\text { tumor }\end{array}$ & $103(42.4)$ \\
\hline Grade 3: no viable cell & $43(17.7)$ \\
\hline \multicolumn{2}{|l|}{ Treatment results } \\
\hline Down staging & $140(57.6)$ \\
\hline Pathological complete response & $43(17 \cdot 7)$ \\
\hline \multicolumn{2}{|l|}{ Adjuvant treatment } \\
\hline Yes & $215(88.5)$ \\
\hline No & $28(11.5)$ \\
\hline
\end{tabular}

Values are presented as number (\%).

$\mathrm{IQR}$, interquartile range.

\section{Pathological results and patient characteristics according to tissue necrosis group}

Tissue necrosis was recorded as follows: CNR in 43 patients (17.7\%), INR in 103 patients (42.4\%), and PNR in 97 patients (39.9\%). Age, sex, and clinical stage were not significantly different between the three tissue response groups. However, perineural and vascular invasion of tumor tissue were more frequently observed in the PNR group $(p<0.005)$. The detailed relationship between clinicopathological features and tissue response are provided in Table 3.

\section{Recurrence and survival patterns in treatment and necrosis response groups}

For the entire cohort, the OS and RFS rates at three years were $74.5 \%$ and $61.3 \%$, respectively. Rates of local and systemic recurrences were related to the treatment response group, with a remarkably low recurrence rate associated with CTR and high recurrence rate related to PTR (Table 4). The 3-year OS rates of the CTR, ITR, and PT'R groups were $83.7 \%, 75.9 \%$, and $69.7 \%$, respectively $(p<0.001)$; the 3-year RFS rates were $76.7 \%, 69.0 \%$, and $52.1 \%$, respectively $(p<0.001$ ) (Fig. $2 A)$.

Rates of local and systemic recurrence were also related to the tissue necrosis group, with a remarkably low recurrence rate associated with CNR and high recurrence rate related to PNR groups (Table 5). The 3-year OS rates of the CNR, INR, and PNR groups were $83.7 \%$, $80.6 \%$, and $61.8 \%$, respectively $(p<0.001)$; the 3 -year RFS rates were $76.7 \%, 68.9 \%$, and $44.3 \%$, respectively ( $p$ $<0.001$ ) (Fig. 2B).

The results of univariate Cox regression analysis for RFS and OS are listed in Table 6. Poor differentiation, lymphatic invasion, perineural invasion, and vascular invasion were associated with RFS and OS. RFS and OS were strongly related to PTR and PNR groups. Compared to CTR, PTR was strongly related to an increased risk of recurrence (hazard ratio [HR], 5.53; 95\% CI, 2.01 to 15.23). Compared to CNR, PNR was strongly related to an increased risk of recurrence (HR, 6.37; 95\% CI, 2.29 to 17.74).

The results of the multivariate Cox regression analysis for RFS and OS are listed in Tables 7 and 8. Multivariate analysis was performed using two models, separately, due to a high association between treatment response and tissue response group. Both PTR and PNR were more strongly associated with RFS and OS than were 
Table 2. Patient and tumor characteristics and treatment response factors $(n=243)$

\begin{tabular}{|c|c|c|c|c|}
\hline Characteristic & $\begin{array}{l}\text { Complete treatment } \\
\text { response (yp'ToNo) }\end{array}$ & $\begin{array}{l}\text { Intermediate treatment } \\
\text { response (yp'T1-2No) }\end{array}$ & $\begin{array}{l}\text { Poor treatment } \\
\text { response (yp'T-4 or } N+)\end{array}$ & $p$ value \\
\hline Total no. of patients & $43(17 \cdot 7)$ & $58(23.9)$ & $142(58.4)$ & \\
\hline Age, yr, median $(\mathrm{IQR})^{\mathrm{a}}$ & $58(48-71)$ & $64(54-71)$ & $62(52-68)$ & 0.326 \\
\hline Sex & & & & 0.847 \\
\hline Male & $25(58.1)$ & $37(63.8)$ & $87(61.3)$ & \\
\hline Female & $18(41.9)$ & $21(36.2)$ & $55(38.7)$ & \\
\hline Clinical stage & & & & 0.021 \\
\hline II & $22(51.2)$ & $36(62.1)$ & $58(40.8)$ & \\
\hline III & $21(48.8)$ & $22(37.9)$ & $84(59.2)$ & \\
\hline \multicolumn{2}{|c|}{ Location of tumor (cm, from anal verge) } & & & 0.776 \\
\hline$<5$ & $14(32.6)$ & $17(29 \cdot 3)$ & $49(34.5)$ & \\
\hline$\geq 5$ & $29(67.4)$ & $41(70.7)$ & $93(65.5)$ & \\
\hline Differentiation & & & & 0.075 \\
\hline Well & $6(14.0)$ & $18(31.0)$ & $21(14.8)$ & \\
\hline Moderate & $30(69.8)$ & $35(60.3)$ & $102(71.8)$ & \\
\hline Poorly & $7(16.3)$ & $5(8.6)$ & $19(13 \cdot 4)$ & \\
\hline \multicolumn{5}{|l|}{ Tumor pathology } \\
\hline Lymphatic invasion & $\mathrm{O}$ & $1(1.7)$ & $34(23.9)$ & $0.000^{\mathrm{a}}$ \\
\hline Perineural invasion & 0 & $1(1.7)$ & $31(21.8)$ & $0.000^{\mathrm{a}}$ \\
\hline Vascular invasion & 0 & 0 & $7(4.9)$ & $0.085^{\mathrm{a}}$ \\
\hline
\end{tabular}

Values are presented as number (\%).

IQR, interquartile range.

${ }^{\mathrm{a}}$ Compared between intermediate and poor response group.

\section{CT'R and CNR.}

\section{DISCUSSION}

The results of this study show that the prognosis of patients after neoadjuvant CRT and radical resection for localized advanced rectal cancer are correlated with necrosis response as well as treatment response.

In both the treatment and necrosis response group, complete response had excellent outcomes with very low rates of local and distant recurrence. Intermediate response patients in both classifications had more improved disease control rates, as compared to the poor response group. In terms of recurrence pattern, the complete and IT'R groups had a remarkably low rate of local recurrence. Local recurrence did not show statistically significant differences among the three treatment response groups. A similar pattern was observed in the three necrosis response groups. Distant metastasis was the main type of recurrence pattern in our study; it was infrequent, occurring in only $7 \%$ of patients in the complete response group.

The difference in systemic recurrence rate between CTR and ITR in the classification of treatment response was not statistically significant. However, the difference in systemic recurrence between CNR and INR was statistically significant. Poor response patients also experienced improved prognosis, as compared to intermediate response patients, in both classifications. That is, distant metastasis showed a statistically significant difference in both response groups, with these differences becoming clearer in the necrosis response group than in the treatment response group.

Recently, in a study of treatment response among patients with locally advanced rectal cancer who were treated with neoadjuvant CRT, pathological evaluation of tumor response to neoadjuvant CRT was found to 
Jung $\mathrm{JH}_{\text {, et al. Response and necrosis in rectal cancer }}$

Table 3. Patient and tumor characteristics and necrosis response factors $(n=243)$

\begin{tabular}{|c|c|c|c|c|}
\hline Characteristic & $\begin{array}{l}\text { Complete necrosis } \\
\text { response (grade } 3 \text { ) }\end{array}$ & $\begin{array}{l}\text { Intermediate necrosis } \\
\text { response (grade } 2 \text { ) }\end{array}$ & $\begin{array}{l}\text { Poor necrosis response } \\
\text { (grade } 1 \text { or } 0 \text { ) }\end{array}$ & $p$ value \\
\hline Total no. of patients & $43(17.7)$ & $103(42.4)$ & $97(39.9)$ & \\
\hline Age, yr, median (IQR) & $58(48-71)$ & $63(53-69)$ & $62(52-69)$ & 0.763 \\
\hline Sex & & & & 0.894 \\
\hline Male & $25(58.1)$ & $64(62.1)$ & $60(61.9)$ & \\
\hline Female & $18(41.9)$ & $39(37 \cdot 9)$ & $37(38.1)$ & \\
\hline Clinical stage & & & & 0.872 \\
\hline II & $22(51.2)$ & $49(47.6)$ & $45(46.4)$ & \\
\hline III & $21(48.8)$ & $54(52.4)$ & $52(53.6)$ & \\
\hline \multicolumn{2}{|c|}{ Location of tumor (cm, from anal verge) } & & & 0.320 \\
\hline$<5$ & $14(32.6)$ & $39(37.9)$ & $27(27.8)$ & \\
\hline$\geq 5$ & $29(67.4)$ & $64(62.1)$ & $70(72.2)$ & \\
\hline Differentiation & & & & 0.016 \\
\hline Well & $6(14.0)$ & $28(27.2)$ & $11(11.3)$ & \\
\hline Moderate & $30(69.8)$ & $60(58.3)$ & $77(79 \cdot 4)$ & \\
\hline Poorly & $7(16.3)$ & $15(14.6)$ & $9(9 \cdot 3)$ & \\
\hline \multicolumn{5}{|l|}{ Tumor pathology } \\
\hline Lymphatic invasion & o & $14(13.6)$ & $21(21.6)$ & $0.134^{\mathrm{a}}$ \\
\hline Perineural invasion & 0 & $10(9.7)$ & $22(22.7)$ & $0.012^{\mathrm{a}}$ \\
\hline Vascular invasion & 0 & $1(1.0)$ & $6(6.2)$ & $0.045^{\mathrm{a}}$ \\
\hline
\end{tabular}

Values are presented as number (\%).

IQR, interquartile range.

${ }^{\mathrm{a}}$ Compared between intermediate and poor response group.

Table 4. Recurrence according to treatment response factors to preoperative chemoradiotherapy $(n=243)$

\begin{tabular}{|c|c|c|c|c|c|c|c|c|c|}
\hline \multirow[t]{2}{*}{ Variable } & \multicolumn{3}{|c|}{$\begin{array}{l}\text { Complete treatment } \\
\text { response (yp'ToNo) }\end{array}$} & \multicolumn{3}{|c|}{$\begin{array}{l}\text { Intermediate treatment } \\
\text { response (yp'1-2No) }\end{array}$} & \multicolumn{3}{|c|}{$\begin{array}{l}\text { Poor treatment } \\
\text { response }\left(\mathrm{yp}_{3}-4 \text { or } \mathrm{N}+\right)\end{array}$} \\
\hline & No. (\%) & HR & $95 \%$ CI & No. (\%) & HR & $95 \%$ CI & No. (\%) & HR & $95 \%$ CI \\
\hline Total no. of patients & $43(17 \cdot 7)$ & & & $58(23.9)$ & & & $142(58.4)$ & & \\
\hline \multicolumn{10}{|l|}{ Recurrence } \\
\hline Local & $1(2.3)$ & & & o & & & $9(6.3)$ & & \\
\hline Systemic & $2(4 \cdot 7)$ & & & $9(15 \cdot 5)$ & & & $41(28.9)$ & & \\
\hline Both & $1(2.3)$ & & & $1(1.7)$ & & & $9(6.3)$ & & \\
\hline Total & $4(9 \cdot 3)$ & & & $10(17.2)$ & & & $59(41.5)$ & & \\
\hline \multicolumn{10}{|c|}{$\begin{array}{l}\text { Cox regression model for } \\
\text { risk of recurrence }\end{array}$} \\
\hline Local & & 1 & & & 0.37 & $0.03-4.07$ & & $3 \cdot 36$ & $0.78-14.48$ \\
\hline Systemic & & 1 & & & 2.46 & $0.68-8.93$ & & 6.26 & $1.95^{-20.06}$ \\
\hline Total & & 1 & & & 1.85 & $0.58-5.89$ & & $5 \cdot 53$ & $2.01-15.23$ \\
\hline
\end{tabular}

HR, hazard ratio; CI, confidence interval. 

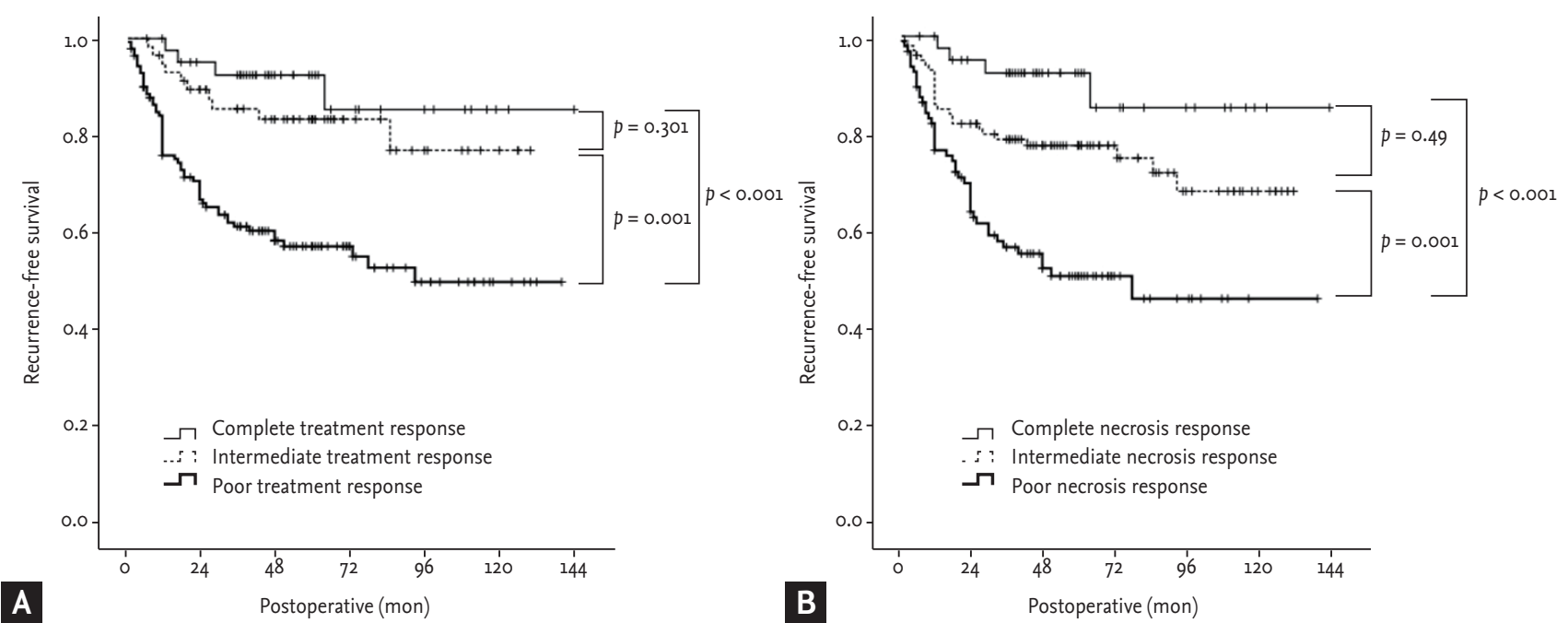

Figure 2. Recurrence-free survival according to treatment response and tissue necrosis groups. (A) Treatment response group, (B) tissue necrosis group.

Table 5. Recurrence according to necrosis response factors to preoperative chemoradiotherapy $(n=243)$

\begin{tabular}{|c|c|c|c|c|c|c|c|c|c|}
\hline \multirow[t]{2}{*}{ Variable } & \multicolumn{3}{|c|}{$\begin{array}{l}\text { Complete necrosis response } \\
\text { (grade } 3 \text { ) }\end{array}$} & \multicolumn{3}{|c|}{$\begin{array}{l}\text { Intermediate necrosis response } \\
\text { (grade 2) }\end{array}$} & \multicolumn{3}{|c|}{$\begin{array}{l}\text { Poor necrosis response } \\
\text { (grade } 1 \text { or o) }\end{array}$} \\
\hline & No. (\%) & HR & $95 \% \mathrm{CI}$ & No. (\%) & HR & $95 \%$ CI & No. $(\%)$ & HR & $95 \% \mathrm{CI}$ \\
\hline Total no. of patients & $43(17.7)$ & & & $103(42.4)$ & & & $97(39.9)$ & & \\
\hline \multicolumn{10}{|l|}{ Recurrence } \\
\hline Local & $1(2.3)$ & & & $2(1.9)$ & & & $7(7.2)$ & & \\
\hline Systemic & $2(4.7)$ & & & $19(18.4)$ & & & $31(32.0)$ & & \\
\hline Both & $1(2.3)$ & & & $4(3.9)$ & & & $6(6.2)$ & & \\
\hline Total & $4(9 \cdot 3)$ & & & $25(24 \cdot 3)$ & & & $44(45 \cdot 4)$ & & \\
\hline \multicolumn{10}{|l|}{$\begin{array}{l}\text { Cox regression model } \\
\text { for risk of recurrence }\end{array}$} \\
\hline Local & & 1 & & & 1.92 & $0.26-6.41$ & & 3.79 & $0.85-16.83$ \\
\hline Systemic & & 1 & & & 3.34 & $1.00-11.14$ & & 7.15 & $2.20-23.20$ \\
\hline Total & & 1 & & & 2.73 & $0.95-7.84$ & & 6.37 & $2.29-17.74$ \\
\hline
\end{tabular}

HR, hazard ratio; CI, confidence interval.

be a powerful early response indicator [10]. In another study, Dworak tumor regression grading was categorized in surgical tissue using a semiquantitative method comparing the amount of viable tumor with the amount of fibrosis [11]. They showed that the complete and intermediate response group exhibited over $25 \%$ regression, suggesting improved disease-free survival after preoperative CRT. However, semiquantitative measurement of tumor regression grade has limitations because it is difficult to generalize. Mandard tumor regression also has this limitation although Santos et al. [13] reported that the Mandard system is more accurate than the Dworak system. In our study, we used the tumor grading system according to percentage of necrosis of tumor cells. We attempted to generalize the tumor grading system but verification of this system in comparison to the Mandard and Dworak tumor regression grading systems will be required for further studies.

In locally advanced rectal cancer, pathological stage and grade of tumor necrosis are known to be prognostic 
Table 6. Univariate Cox proportional hazards regression models of clinical factors of RFS and OS

\begin{tabular}{|c|c|c|c|c|}
\hline \multirow{2}{*}{ Factor } & \multicolumn{2}{|c|}{ RFS } & \multicolumn{2}{|c|}{ OS } \\
\hline & HR & $95 \%$ CI & HR & $95 \%$ CI \\
\hline \multicolumn{5}{|l|}{ Treatment response } \\
\hline Complete response & 1 & & 1 & \\
\hline Intermediate response & 1.85 & $0.58-5.89$ & 2.02 & $0.64-6.36$ \\
\hline Poor response & $5 \cdot 53$ & $2.01-15.23$ & 3.89 & $1.39-10.80$ \\
\hline \multicolumn{5}{|l|}{ Necrosis response } \\
\hline Complete response & 1 & & 1 & \\
\hline Intermediate response & 2.73 & $0.95-7.84$ & 1.78 & $0.60-5.27$ \\
\hline Poor response & 6.37 & $2.29-17.74$ & $5 \cdot 48$ & $1.96-15.37$ \\
\hline \multicolumn{5}{|l|}{ Clinical stage } \\
\hline II & 1 & & & \\
\hline III & 1.55 & $0.97-2.47$ & 1.68 & $1.00-2.82$ \\
\hline \multicolumn{5}{|l|}{ Differentiation } \\
\hline Well & 1 & & & \\
\hline Moderate & 0.97 & $0.53-1.80$ & 1.13 & $0.55^{-2.33}$ \\
\hline Poorly & 1.48 & $0.67-3.24$ & 2.50 & $1.08-5.78$ \\
\hline \multicolumn{5}{|l|}{ Lymphatic invasion } \\
\hline None & 1 & & & \\
\hline Present & 2.65 & $1.55-4.52$ & 1.61 & $0.86-3.03$ \\
\hline \multicolumn{5}{|l|}{ Perineural invasion } \\
\hline None & 1 & & & \\
\hline Present & 1.87 & $1.04-3.35$ & 2.04 & $1.11-3.77$ \\
\hline \multicolumn{5}{|l|}{ Vascular } \\
\hline None & 1 & & & \\
\hline Present & 4.25 & $1.71-10.60$ & 3.03 & $1.09-8.41$ \\
\hline \multicolumn{5}{|c|}{ Location of tumor (cm, from anal verge) } \\
\hline$<5$ & 1 & & & \\
\hline$\geq 5$ & 1.45 & $0.91-2.31$ & 0.74 & $0.44-1.23$ \\
\hline
\end{tabular}

RFS, recurrence free survival; OS, overall survival; HR, hazard ratio; CI, confidence interval.

indicators of treatment response. However, there have been no studies directly comparing these two prognostic indicators in the same cohort using the same statistical method. In our study, we evaluated the two prognostic indicators in one cohort of rectal cancer patients and compared the two indicators using two models in a multivariate analysis with the Cox regression model. The HR of the PTR group was 4.42 (95\% CI, 1.57 to 12.44) and that of the PNR group was 5.56 (95\% CI, 1.95 to 15.84) in the multivariate Cox proportional hazard model of RFS. For OS, the HR was 3.39 (95\% CI, 1.18 to 9.70) in the PTR group and 6.20 (95\% CI, 2.15 to 17.92) in the PNR group. This means that the PNR group had a high HR, as compared to the PTR group, for RFS and OS. Therefore, survival curves for recurrence and for treatment response were separate in terms of necrosis response.

Previous studies of prognosis associated with the resection of advanced rectal cancer have some limitations due to the data being pooled from multiple smaller series [12,14]. Our study is a single-institutional study in which the patients were all treated by the same surgical team and a single treatment strategy. Although our study may overlook potential limitations related to an 8-year study period, the biases of these results were min- 
Table 7. Multivariate Cox proportional hazards regression models of clinical factors of recurrence free survival

\begin{tabular}{|c|c|c|c|c|}
\hline \multirow{2}{*}{ Factor } & \multicolumn{2}{|c|}{ Model 1 (treatment response) } & \multicolumn{2}{|c|}{ Model 2 (necrosis response) } \\
\hline & $\mathrm{HR}$ & $95 \% \mathrm{CI}$ & HR & $95 \% \mathrm{CI}$ \\
\hline \multicolumn{5}{|c|}{ Treatment and necrosis response } \\
\hline Complete response & 1 & & 1 & \\
\hline Intermediate response & 1.87 & $0.58-6.00$ & 2.21 & $0.76-6.45$ \\
\hline Poor response & $4 \cdot 42$ & $1.57-12.44$ & $5 \cdot 56$ & $1.95^{-15.84}$ \\
\hline \multicolumn{5}{|l|}{ Clinical stage } \\
\hline II & 1 & & 1 & \\
\hline III & 1.29 & $0.77-2.16$ & 1.62 & $0.96-2.74$ \\
\hline \multicolumn{5}{|l|}{ Differentiation } \\
\hline Well & 1 & & 1 & \\
\hline Moderate & 0.82 & $0.44^{-1.54}$ & 0.71 & $0.37-1.36$ \\
\hline Poorly & 1.21 & $0.54-2.72$ & 1.27 & $0.56-2.88$ \\
\hline \multicolumn{5}{|l|}{ Lymphatic invasion } \\
\hline None & 1 & & 1 & \\
\hline Present & 1.58 & $0.89-2.81$ & 1.76 & $0.98-3.13$ \\
\hline \multicolumn{5}{|l|}{ Perineural invasion } \\
\hline None & 1 & & 1 & \\
\hline Present & 1.03 & $0.55-1.94$ & 1.00 & $0.53-1.90$ \\
\hline \multicolumn{5}{|l|}{ Vascular } \\
\hline None & 1 & & 1 & \\
\hline Present & 3.15 & $1.19-8.32$ & 2.52 & $0.95-6.73$ \\
\hline \multicolumn{5}{|c|}{ Location of tumor (cm, from anal verge) } \\
\hline$<5$ & 1 & & 1 & \\
\hline$\geq 5$ & 0.65 & $0.40-1.07$ & 0.56 & $0.34-0.92$ \\
\hline
\end{tabular}

HR, hazard ratio; CI, confidence interval.

imized by employing the same radiation dose, the same type of concurrent chemotherapy, and homogenous adjuvant chemotherapy.

One of the common issues in advanced rectal cancer treatment is adjuvant chemotherapy. The PROCTOR/ SCRIPT study did not show a significant difference in OS between adjuvant chemotherapy and the observation group in a multicenter randomized trial of 470 patients with stage II or III rectal cancer. An Italian trial also reported no difference in 10-year OS between adjuvant chemotherapy and observation $[15,16]$. Recently, the EORTC 22921 trial also reported that adjuvant fluorouracil-based chemotherapy after neoadjuvant radiotherapy (with or without chemotherapy) did not demonstrate a significant effect on disease-free survival and OS in advanced rectal cancer patients [17]. Two previous trials have only been reported as abstracts and the results of the EORTC 22921 trial are controversial because of poor adherence to treatment protocols and a suboptimal schedule. Over half of the patients in the EORTC 22921 trial did not receive the intended four cycles. However, the high rate of distant metastasis in PTR and PNR shows the necessity for effective adjuvant chemotherapy in our study. Hong et al. [18] reported the effectiveness of FOLFOX adjuvant chemotherapy in postoperative pathological stage II or III rectal cancer.

In our study, $88.5 \%$ of patients received adjuvant chemotherapy after CRT and surgery. The most common reasons for not receiving adjuvant chemotherapy were poor performance status or surgical complications. Evaluation of the effect of adjuvant therapy is beyond the scope of our study because most patients received 
Table 8. Multivariate Cox proportional hazards regression models of clinical factors of overall survival

\begin{tabular}{|c|c|c|c|c|}
\hline \multirow{2}{*}{ Factor } & \multicolumn{2}{|c|}{ Model 1 (treatment response) } & \multicolumn{2}{|c|}{ Model 2 (necrosis response) } \\
\hline & HR & $95 \% \mathrm{CI}$ & HR & $95 \% \mathrm{CI}$ \\
\hline \multicolumn{5}{|c|}{ Treatment and necrosis response } \\
\hline Complete response & 1 & & 1 & \\
\hline Intermediate response & 2.37 & $0.75-7.52$ & 1.53 & $0.51-4.62$ \\
\hline Poor response & $3 \cdot 39$ & $1.18-9.70$ & 6.20 & $2.15-17.92$ \\
\hline \multicolumn{5}{|l|}{ Clinical stage } \\
\hline II & 1 & & 1 & \\
\hline III & 1.64 & $0.93-2.91$ & 2.06 & $1.15-3.70$ \\
\hline \multicolumn{5}{|l|}{ Differentiation } \\
\hline Well & 1 & & 1 & \\
\hline Moderate & 1.11 & $0.53-2.31$ & 0.75 & $0.35-1.61$ \\
\hline Poorly & 2.58 & $1.08-6.15$ & 2.62 & $1.11-6.21$ \\
\hline \multicolumn{5}{|l|}{ Lymphatic invasion } \\
\hline None & 1 & & 1 & \\
\hline Present & 0.85 & $0.43-1.68$ & 0.84 & $0.42-1.67$ \\
\hline \multicolumn{5}{|l|}{ Perineural invasion } \\
\hline None & 1 & & 1 & \\
\hline Present & 1.38 & $0.70-2.71$ & 1.18 & $0.60-2.31$ \\
\hline \multicolumn{5}{|l|}{ Vascular } \\
\hline None & 1 & & 1 & \\
\hline Present & 2.68 & $0.90-7.92$ & 2.05 & $0.70-6.04$ \\
\hline \multicolumn{5}{|c|}{ Location of tumor (cm, from anal verge) } \\
\hline$<5$ & 1 & & 1 & \\
\hline$\geq 5$ & 0.61 & $0.35^{-1.07}$ & 0.51 & $0.29-0.88$ \\
\hline
\end{tabular}

HR, hazard ratio; CI, confidence interval.

adjuvant chemotherapy. Generally, we think that complete response patients receiving neoadjuvant CRT have a very favorable prognosis, while uncertainty remains about any additional gain from adjuvant chemotherapy in this group. However, a clinical trial of the poor response group is needed to evaluate whether toxicity is increased along with treatment intensification.

In conclusion, the treatment response factor and necrosis response factor were compared using the same statistical method in the same cohort of advanced rectal cancer patients receiving neoadjuvant CRT and surgery. We found that the prognostic value of the necrosis response factor was as important as that of treatment response factor in rectal cancer patients treated with neoadjuvant CRT.

\section{KEY MESSAGE}

1. In both the treatment and necrosis response group, complete response had excellent outcomes with very low rates of local and distant recurrence.

2. The difference in systemic recurrence rate between complete treatment response and intermediate treatment response in the classification of treatment response was not statistically significant. However, the difference in systemic recurrence between complete necrosis response and intermediate necrosis response was statistically significant.

3. The prognostic value of the necrosis response factor was as important as that of treatment re- 
sponse factor in rectal cancer patients treated with neoadjuvant chemoradiotherapy.

\section{Conflict of interest}

No potential conflict of interest relevant to this article was reported.

\section{REFERENCES}

1. Kockerling F, Reymond MA, Altendorf-Hofmann A, Dworak O, Hohenberger W. Influence of surgery on metachronous distant metastases and survival in rectal cancer. J Clin Oncol 1998;16:324-329.

2. Nuyttens JJ, Robertson JM, Yan D, Martinez A. The influence of small bowel motion on both a conventional three-field and intensity modulated radiation therapy (IMRT) for rectal cancer. Cancer Radiother 2004;8:297304 .

3. Arbea L, Ramos LI, Martinez-Monge R, Moreno M, Aristu J. Intensity-modulated radiation therapy (IMRT) vs. 3D conformal radiotherapy (3DCRT) in locally advanced rectal cancer (LARC): dosimetric comparison and clinical implications. Radiat Oncol 2010;5:17.

4. Samuelian JM, Callister MD, Ashman JB, Young-Fadok TM, Borad MJ, Gunderson LL. Reduced acute bowel toxicity in patients treated with intensity-modulated radiotherapy for rectal cancer. Int J Radiat Oncol Biol Phys 2012;82:1981-1987.

5. O'Connell JB, Maggard MA, Liu JH, Etzioni DA, Ko CY. Are survival rates different for young and older patients with rectal cancer? Dis Colon Rectum 2004;47:2064-2069.

6. Rodel C, Liersch T, Becker H, et al. Preoperative chemoradiotherapy and postoperative chemotherapy with fluorouracil and oxaliplatin versus fluorouracil alone in locally advanced rectal cancer: initial results of the German CAO/ARO/AIO-O4 randomised phase 3 trial. Lancet Oncol 2012;13:679-687.

7. Chua YJ, Barbachano Y, Cunningham D, et al. Neoadjuvant capecitabine and oxaliplatin before chemoradiotherapy and total mesorectal excision in MRI-defined poor-risk rectal cancer: a phase 2 trial. Lancet Oncol 2010;11:241-248.

8. Klautke G, Feyerherd P, Ludwig K, Prall F, Foitzik T, Fietkau R. Intensified concurrent chemoradiotherapy with 5-fluorouracil and irinotecan as neoadjuvant treatment in patients with locally advanced rectal cancer. Br J Cancer 2005;92:1215-1220.

9. Silberfein EJ, Kattepogu KM, Hu CY, et al. Long-term survival and recurrence outcomes following surgery for distal rectal cancer. Ann Surg Oncol 2010;17:2863-2869.

10. Park IJ, You YN, Agarwal A, et al. Neoadjuvant treatment response as an early response indicator for patients with rectal cancer. J Clin Oncol 2012;30:1770-1776.

11. Rodel C, Martus P, Papadoupolos T, et al. Prognostic significance of tumor regression after preoperative chemoradiotherapy for rectal cancer. J Clin Oncol 2005;23:86888696.

12. Maas M, Nelemans PJ, Valentini V, et al. Long-term outcome in patients with a pathological complete response after chemoradiation for rectal cancer: a pooled analysis of individual patient data. Lancet Oncol 2010;11:835-844.

13. Santos MD, Silva C, Rocha A, Matos E, Nogueira C, Lopes C. Prognostic value of mandard and dworak tumor regression grading in rectal cancer: study of a single tertiary center. ISRN Surg 2014;2014:310542.

14. Capirci C, Valentini V, Cionini L, et al. Prognostic value of pathologic complete response after neoadjuvant therapy in locally advanced rectal cancer: long-term analysis of 566 ypCR patients. Int J Radiat Oncol Biol Phys 2008;72:99-107.

15. Breugom AJ, van den Broek CB, van Gijn W, et al. The value of adjuvant chemotherapy in rectal cancer patients after preoperative radiotherapy or chemoradiation followed by TME-surgery: the PROCTOR/SCRIPT study. Eur J Cancer 2013;49(Suppl 3):S1.

16. Cionini L, Sainato A, De Paoli A, et al. Final results of randomized trial on adjuvant chemotherapy after preoperative chemoradiation in rectal cancer. Radiother Oncol 2010;96(Suppl 1):S113-S114.

17. Bosset JF, Calais G, Mineur L, et al. Fluorouracil-based adjuvant chemotherapy after preoperative chemoradiotherapy in rectal cancer: long-term results of the EORTC 22921 randomised study. Lancet Oncol 2014;15:184-190.

18. Hong YS, Nam BH, Kim KP, et al. Oxaliplatin, fluorouracil, and leucovorin versus fluorouracil and leucovorin as adjuvant chemotherapy for locally advanced rectal cancer after preoperative chemoradiotherapy (ADORE): an open-label, multicentre, phase 2, randomised controlled trial. Lancet Oncol 2014;15:1245-1253. 